\title{
Finite element analysis of reinforced concrete bridge pier subjected to seismic loading
}

\author{
Hayder Ala'a Hasan ${ }^{1}$, Ammar A. Abdul Rahman ${ }^{1}$ and Hani Aziz Ameen ${ }^{2}$ \\ ${ }^{1}$ Civil Engineering Department, Nahrain University, Baghdad, Iraq \\ ${ }^{2}$ Dies and Tools Dept., Technical College, Baghdad, Iraq
}

\begin{abstract}
The evaluation of the damage caused by seismic action, to existing bridges has received an important attention in recent years, because it is the first step towards reducing casualties and economic losses. All reinforced concrete bridges in Iraq which have been constructed were designed by outdated building codes that did not account for large seismic activities and were designed with typical transverse reinforcement spacing that far exceed today's standards and are therefore insufficient to resist the laterally applied loads. The evaluation of the damage caused by earthquakes in existing bridges became necessary in Iraq especially after the huge earthquakes in the neighbor countries such as Bam earthquake in Iran on 26 December 2003 with a magnitude $M w=6.6$ and Van Earthquake in Turkey on 23 October 2011 with a magnitude $\mathrm{Mw}=7.2$. Therefore, this finite element analysis will involve modeling a typical scaled version of a reinforced concrete bridge pier that is usually being used in typical bridges in Iraq. The pier will have a vertical load applied at the top to simulate the dead loads of the superstructure and will also be subjected to seismic loading. The main objective of this study is to investigate the damage in the typical reinforced concrete bridge pier under seismic loads of intensity same as that happened in the area around Iraq and see whether it will support such an earthquake or not.
\end{abstract}

\section{INTRODUCTION}

Most of the bridges in Iraq were inadequately designed to resist earthquakes for two reasons. The first one is the insufficient lap splice length placed at the base of the pier columns and the other is the widely spaced transverse reinforcement in the columns as shown in Figure-1 working for minimum requirements in structural R.C. design. In the existing Building Code Requirements for Structural Concrete, ACl 318-08 [3] widely used in Iraq, lap splices are required in the center half of the member length. The behavior of a statically indeterminate structure subjected to earthquake loading is such that after the moment strengths at one or more points have been reached, discontinuities develop, commonly known as "plastic hinges", in the elastic curve at those points, which results in an inelastic analysis [3]. With the insufficient lap splice length at the base of the columns in the plastic hinge region and lack of confinement provided by the transverse

\section{FINITE ELEMENT ANALYSIS}

\section{SPECIMEN GEOMETRY}

The finite element analysis included modeling of a typical bridge pier and its piles foundation (with pile cap) and soil with the actual dimensions and reinforcement, the longitudinal reinforcement is not able to develop its desired strength and spalling of the concrete will occur, which will result in debonding and initiate slippage. Ultimately the base of the column can either experience a brittle shear failure, or a brittle pullout failure.

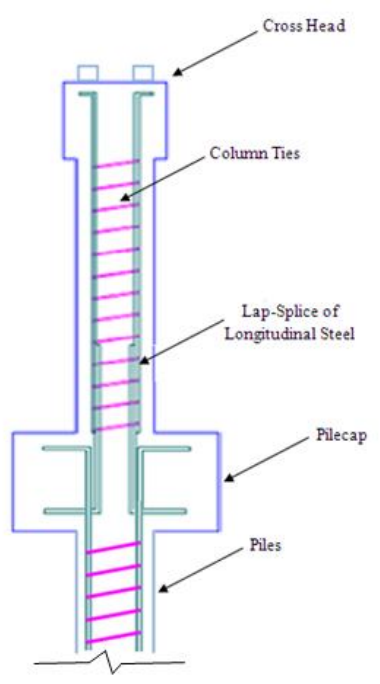

Figure-1. Lap splice

properties corresponding to "Sheikh Sa'ad bridge" in "Sheikh Sa'ad" district at "Wasit" governorate 
Am. J. Sci. Ind. Res., 2012, 3(2): 94-98

$70 \mathrm{~km}$ south of the "Kut" city, Iraq Table-1 and Table-2.

Table-1: Details of Piles and Columns of Typical Pier

\begin{tabular}{|c|c|c|c|c|}
\hline & $\begin{array}{c}\text { Diameter } \\
(\mathrm{m})\end{array}$ & $\begin{array}{c}\text { Length } \\
(\mathrm{m})\end{array}$ & $\begin{array}{c}\text { Longitudinal } \\
\text { Reinforcement }\end{array}$ & Stirrups \\
\hline Pile & 1.5 & 17 & $55 \varphi 25$ & $\begin{array}{c}\varphi 10 / 150 \\
\text { pitch }\end{array}$ \\
\hline Column & 1.2 & 5 & $40 \varphi 25$ & $\begin{array}{c}\varphi 10 / 150 \\
\text { pitch }\end{array}$ \\
\hline
\end{tabular}

Table-2: Details of Pile cap, Cross head and Pads

\begin{tabular}{|c|c|c|c|c|c|c|}
\hline & $\begin{array}{l}\text { Length } \\
(\mathrm{m})\end{array}$ & $\begin{array}{l}\text { Width } \\
(\mathrm{m})\end{array}$ & $\begin{array}{l}\text { Depth } \\
\text { (m) }\end{array}$ & $\begin{array}{l}\text { Positive } \\
\text { Rein. }\end{array}$ & $\begin{array}{c}\text { Negative } \\
\text { Rein. }\end{array}$ & Stirrups \\
\hline $\begin{array}{l}\text { Pile } \\
\text { cap }\end{array}$ & 12 & 2 & 1.5 & $9 \varphi 25$ & $9 \varphi 25$ & $\varphi 12 / 200$ \\
\hline $\begin{array}{l}\text { Cross } \\
\text { Head }\end{array}$ & 12 & 2 & 1.6 & $9 \varphi 25$ & $12 \varphi 25$ & $\varphi 16 / 150$ \\
\hline Pads & 0.5 & 0.4 & 0.2 & \multicolumn{2}{|c|}{$4 \varphi 16$} & - \\
\hline
\end{tabular}

In spite of the symmetry in cross-section of the concrete bridge substructure, symmetry was not utilized in the finite element analysis due to the unsymmetrical loads. Therefore, the whole bridge substructure and the surrounding soil were modeled. The ANSYS software will be used to develop the model geometries as shown in Figure2.

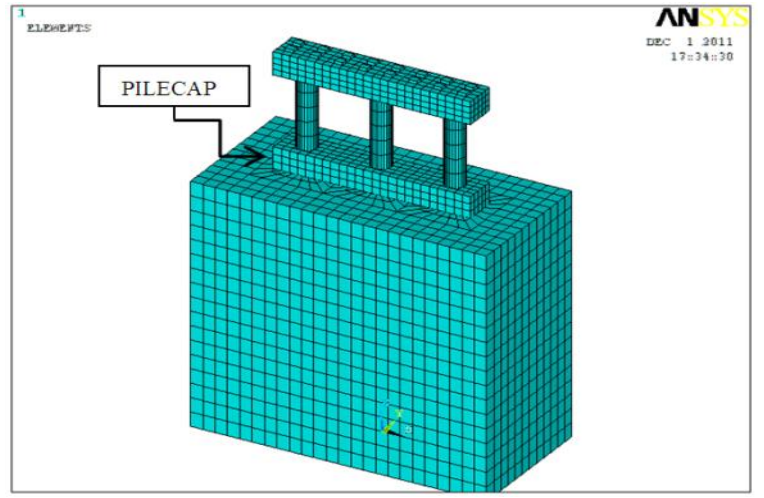

Figure-2: Bridge Pier Model

Ansys Modeling: The case under study was modeled using the SOLID65 concrete element, which is used for modeling three dimensional solid models with or without rebars. The element is capable of cracking, crushing, plastic deformation, and creep in tension and compression using the non-linearity material properties as shown in Figure$3[4]$.

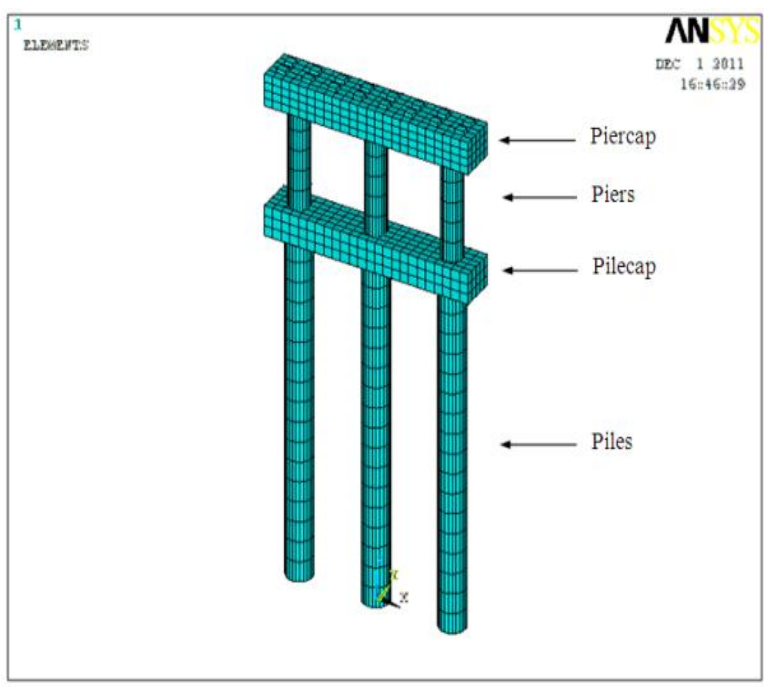

Figure-3: Pier Concrete Parts

SOLID45 element was used to model two soil layers (silt and clay) as volumes. The soil model is $18 \mathrm{~m}$ long, $9 \mathrm{~m}$ width and $17 \mathrm{~m}$ depth. The distances between center to center of piles are equal to $4.5 \mathrm{~m}$. Since the diameter of piles is $1.5 \mathrm{~m}$, therefore distances between the centers of piles and the edges of soil volume is $4.5 \mathrm{~m}$ which is equal to three times the diameter of piles. The effect of soil can be neglected beyond this distance as shown in figure4. The SOLID45 element has plasticity, creep, swelling, stress stiffening, large deflection, and large strain capabilities [4].

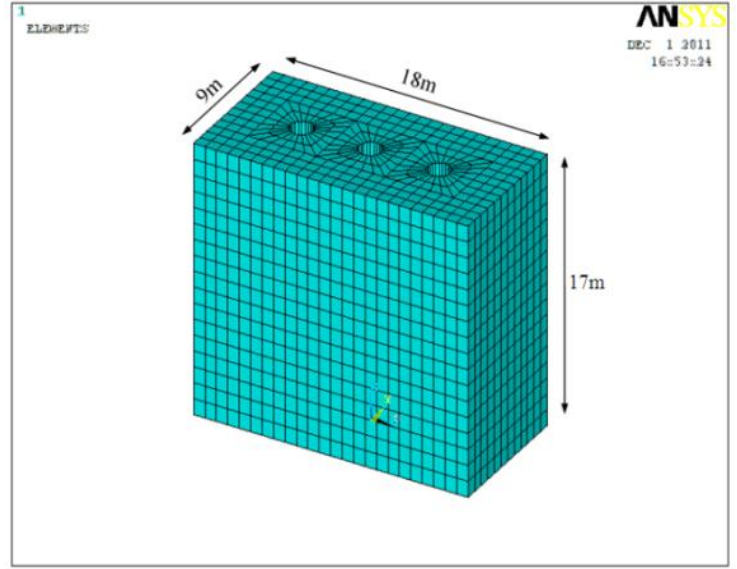

Figure-4: Soil Model 
Am. J. Sci. Ind. Res., 2012, 3(2): 94-98

Rigid-to-flexible contact model was used to contact between the piles and the soil. In rigid-to-flexible contact problems, one or more of the contacting surfaces are treated as rigid (i.e., it has a much higher stiffness relative to the deformable body it contacts). In general, any time a soft material comes in contact with a hard material, the problem may be assumed to be rigid-to-flexible. In this study the concrete was considered the rigid material and the soil was the flexible (soft) one. A surface-tosurface contact model was used in this study. This contact model supports both rigid-to-flexible and flexible-to-flexible, surface-to-surface contact elements. These contact elements use a "target surface" and a "contact surface" to form a contact pair. The target surface is modeled with TARGE170 element and the contact surface is modeled with CONAC174 element as shown in Figure-5 [4].

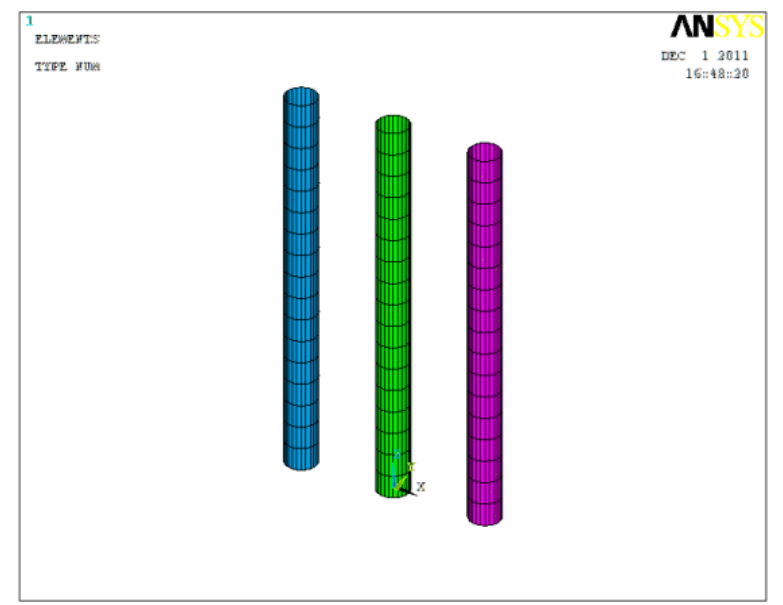

Figure -5: Contact Elements between Piles and Soil

The SOLID65 element uses a smeared rebar capability, which involves three different rebar materials orientated in any direction relative to the global coordinate system. The rebar was input to replicate the volumetric ratios and orientation of the longitudinal and transverse reinforcement in the typical bridge column [4]. The material properties of the model is shown in the Table-3

Loading And Constraints: The SOLID45 and SOLID65 elements which are used to model the soil and concrete respectively have three translational degrees of freedom. All of them were restrained at the sides and the base of the soil volume. Also the bottoms of the piles were restrained to simulate the real boundary conditions in situ.

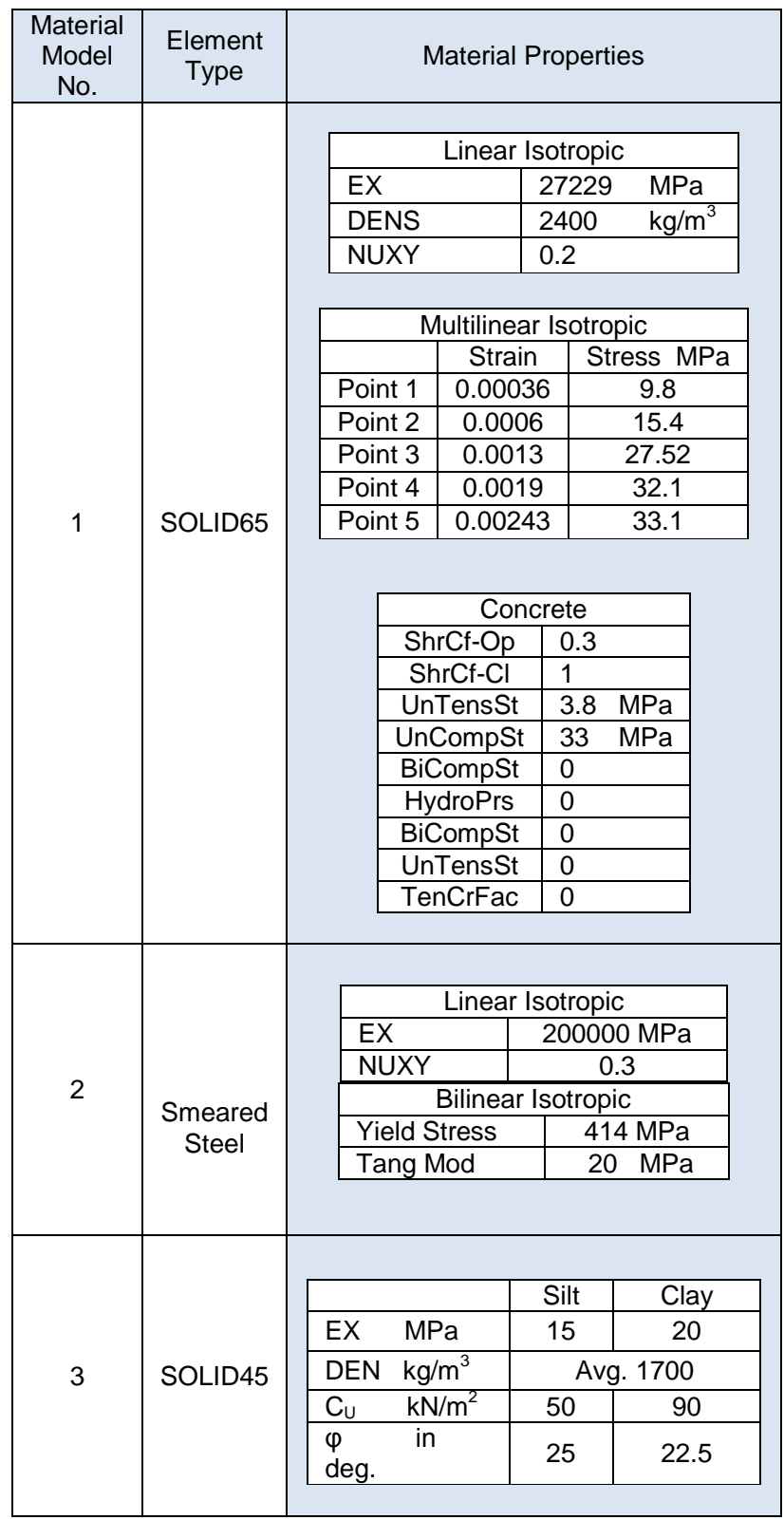

Table-3: Material Properties

Two types of loadings were applied on the the model; the loads of the superstructure of the bridge were applied on the 16 pads distributed on the cross head. The superstructure laod was applied as surfase pressure of $0.5 \mathrm{MPa}$ for each pad. The earthquake ground motion was applied as lateral forces at the top of piles which was computed by multiplying response acceleration by the inertia masses shown in Figure-6 [5]. Dohuk (a governorate north of Iraq) earthquake happened in 
2008 with magnitude $\mathrm{Mw}=3.8$ will be the input ground motion for this study to give a realistic

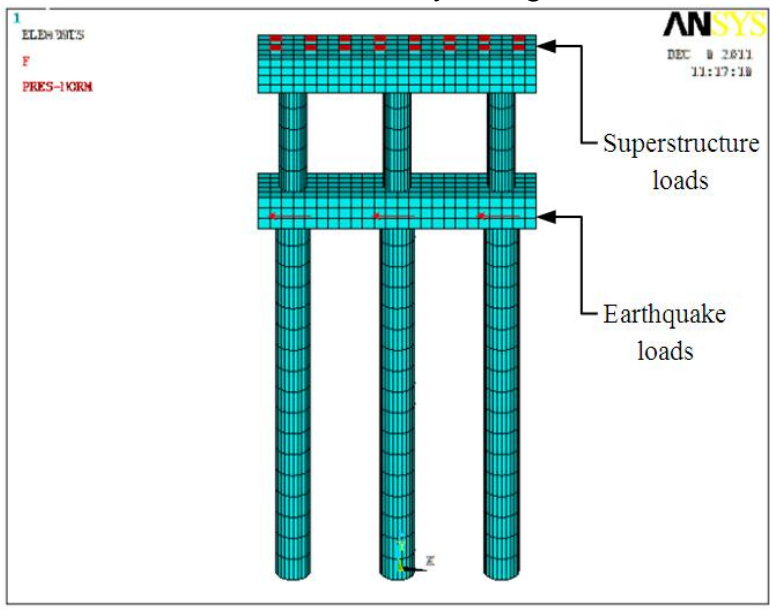

Figure-6: Applied Loads

Solution analysis type: A full transient dynamic analysis will be utilized to perform a non-linear seismic analysis of the reinforced concrete pier. A small displacement transient analysis was required when using a SOLID65 element to gain more accurate results. Such analyses are computational expensive. However, they will give results based on the dynamic equation of equilibrium and hence both positive (tensile) and negative (compressive) stress results will be reported for the full length of the earthquake. Automatic time stepping was used and a minimum and maximum time step was specified to equal 0.0002 and $0.1 \mathrm{sec}$ respectively and the load steps were ramped.

Test results: The maximum stresses had occurred at the top of the piles (at the points on which the earthquake effects were applied). These stresses exceeding the concrete compressive strength and therefore causing the cracks shown in Figure-7

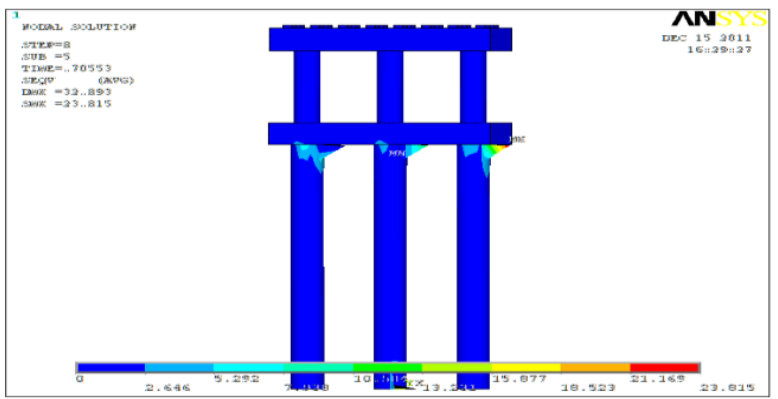

Figure-7: Stresses Distribution response to an existing bridge in Iraq.

The cracks had occurred at the top of the piles and at the bottom of pile cap where the displacement had reached $32.893 \mathrm{~mm}$ as shown in Figure-8

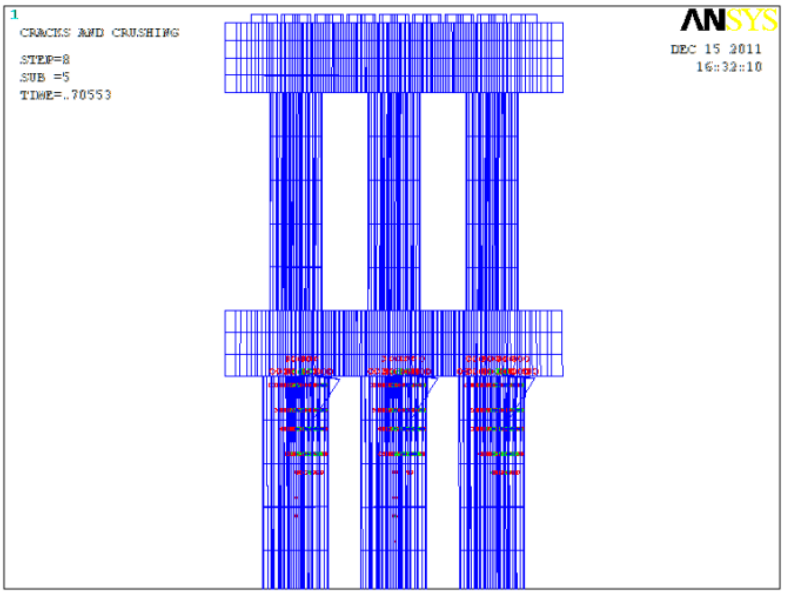

Figure-8: Cracks Distribution

The deflection in the longitudinal direction at the top of the pier (X-direction) and the transverse deflection (Y-direction) of the pier are shown in Figures 9 and 10 respectively.

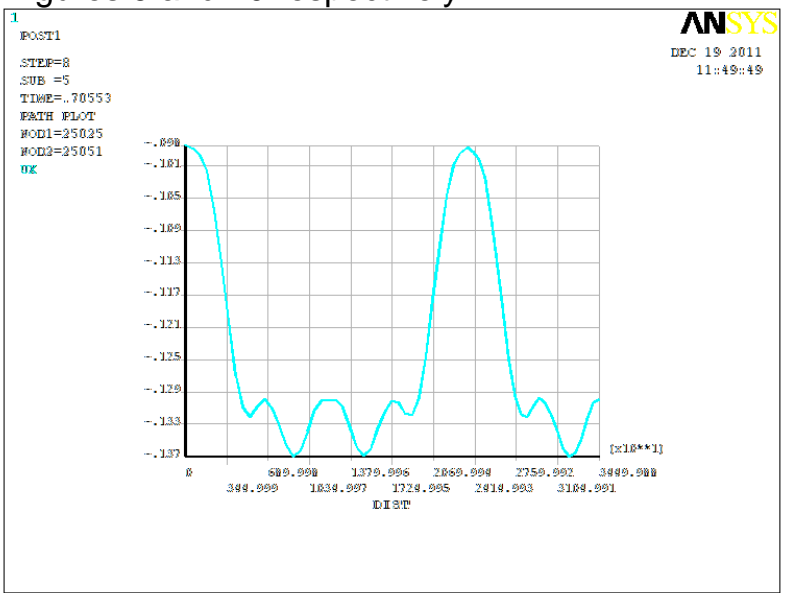

Figure-9: X Deflection along Piercap Length

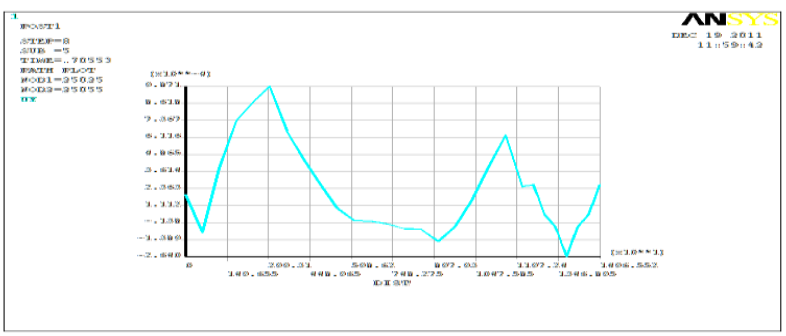

Figure-10: Y Deflection along Piercap Width 
Am. J. Sci. Ind. Res., 2012, 3(2): 94-98

Conclusions: From the results obtained it was clear that the deflections are small and within allowable limits, but the stresses in the concrete were higher than the limits of the structural concrete design limits of the general codes of practice, keeping in mind the earthquake load applied was not severe compared to earthquake happened near Iraq area.

It is highly recommended to force bridge designers in Iraq to use and depend on the special provisions for earthquakes in codes to cover such deficiencies in pier design.

Further investigation: It is also highly recommended to extend this study by taking the displacements took place at the level of the pads beneath the superstructure and apply them at the superstructure to investigate the response and strength of the bridge deck.

\section{REFRENCES}

1. Sergio Oller, Alex H. Barbat, (2005), "Momentcurvature damage model for bridges subjected to seismic loads", Elsevier B.V.

2. Benjamin M. Schlick, (2002), "Finite Element Analysis of Reinforced Concrete Bridge Pier Columns Subjected To Seismic Loading", Department of Civil and Environmental Engineering, University of Massachusetts Amherst.

3. "Building Code Requirements for Structural Concrete and Commentary, (2008) (American Concrete Institute $\mathrm{ACl}$ 318-08), Farmington Hills, Michigan.

4. SAS (2009), "ANSYS 12.1 Finite Element Analysis System Help", SAS IP, Inc

5. Anil K. Chopra, (1980), "Dynamics of Structures $A$ Primer", Earthquake Engineering Research Institute, University of California, Berkeley. 